\title{
Экономика труая
}

удк 005

СЛЕПЦОВА ЕКАТЕРИНА ВИКТОРОВНА

к.э.н., дочент ФГБОУ ВО «Кубанский государственный университет», e-mail: sleptsova.kat@yandex.ru

ТРОФИМЕНКО СТЕПЕН СЕРГЕЕВИЧ магистрант ФГБОУ ВО «Кубанский государственный университет», e-mail: stepanTroff@gmail.com

РОГАЧЕВ ПАВЕА ДМИТРИЕВИЧ магистрант ФГБОУ ВО «Кубанский государственный университет», e-mail: Rogachev.pavel@gmail.com

КОНДАКОВ ОЛЕГ ОЛЕГОВИЧ

магистрант ФГГБОУ ВО «Кубанский государственный университет», e-mail:kondakov@mail.ru

\section{ТЕОРЕТИЧЕСКИЕ АСПЕКТЫ ИССАЕАОВАНИЯ КАЮЧЕВЫХ ПРОБАЕМ УПРАВАЕНИЯ ПЕРСОНААОМ}

Аннотауия. Целью работы служит исследование теоретических аспектов ключевых проблем управления персоналом. Исследование основывается на общенаучной методологии, которая предусматривает применение комплексного подхода к решению проблем. Основой данной работы выступают фундаментальные труды отечественных и зарубежных ученых по проблемам управления персоналом в условиях экономических ограничений для

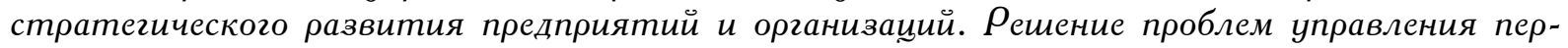
соналом на основе актуализации профессиональной ориентащии человеческих ресурсов обусловливается развитием профессионального потенциала сотрудников, повышением эффективности стимулирующих факторов в управлении персоналом и формированием синергетического эффекта от внедрения новых рабочих мест. Именно реализация нового контура исследования профессиональных человеческих ресурсов как наиболее мобильной и адаптивной части практики управления персоналом позволит решать вопросы оптимизачии спроса на труд и его предложения при одновременном обеспечении производительности персонала. Доказано, что управление персоналом представляет собой целенаправленное управленческое воздействие руководящего состава и кадровой службы, направленное на

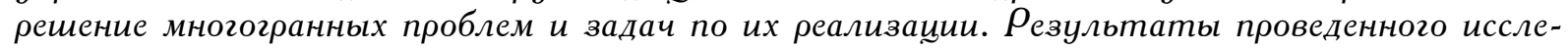
дования могут использоваться для формирования системы управления персоналом пред-

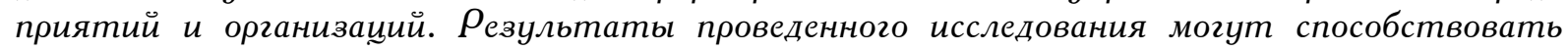
разработке нового научного направления, относящегося к взаимно-продуктивному управлению человеческими ресурсами организачий и предприятий. Новые технологии управления персоналом позволят работодателям быстрее и надежнее общаться с сотрудниками и разрабатывать инноващионные HR-тактики. Модернизащия структуры управления персоналом представляет собой сложную и ответственную задачу для руководства, поэтому иелесообразно в современных нестабильных условиях хозяйствования акиентировать внимание на решении проблем управления персоналом.

Ключевые слова: управление персоналом, кадровая политика, рабочее место, условия труда, декомпозищия $H R$-прочессов, кадровое планирование. e-mail: sleptsova.kat@yandex.ru 
TROFIMENKO STEPAN SERGEEVICH master's student of FSBEI HE "Kuban state University», e-mail: stepanTroff@gmail.com

ROGACHEV PAVEL DMITRIEVICH master's student of FSBEI HE "Kuban state University», e-mail: Rogachev.pavel@gmail.com

KONDAKOV OLEG OLEGOVICH master's student of FSBEI HE "Kuban state University», e-mail:kondakov@mail.ru

\title{
THEORETICAL ASPECTS OF KEYWORD RESEARCH PROBLEMS OF PERSONNEL MANAGEMENT
}

\begin{abstract}
The aim of the work is to study the theoretical aspects of the key problems of personnel management. The study is based on General scientific methodology, which provides an integrated approach to problem solving. The basis of this work are the fundamental works of domestic and foreign scientists on the problems of personnel management in terms of economic constraints for the strategic development of enterprises and organizations. The solution of problems of personnel management on the basis of actualization of professional orientation of human resources is due to the development of professional potential of employees, increasing the efficiency of incentive factors in personnel management and the formation of a synergetic effect from the introduction of new jobs. It is the implementation of a new research circuit of professional human resources as the most mobile and adaptive part of the practice of personnel management that will allow to solve the problems of optimizing the demand for labor and its supply while ensuring the productivity of personnel. It is proved that personnel management is a purposeful management impact of the management team and personnel service, aimed at solving multifaceted problems and tasks for their implementation. The results of the study can be used to form a personnel management system of enterprises and organizations. The results of the study can contribute to the development of a new scientific direction related to the mutually productive management of human resources of organizations and enterprises. New technologies of personnel management will allow employers to communicate faster and more reliably with employees and develop innovative $H R$ tactics. Modernization of the personnel management structure is a complex and responsible task for management, so it is advisable in today's unstable economic conditions to focus on solving the problems of personnel management.
\end{abstract}

Keywords: personnel management; personnel policy; workplace; working conditions; decomposition of $H R$ processes; personnel planning.

Введение. Управление персоналом остается самым сложным объектом в менеджменте, который включает в себя принципы, методы и формы воздействия, образуя общую систему с целью улучшения результатов при выполнении трудовых обязанностей.

Методы исследования. В статье были использованы следующие методы исследования: статистический, аналитический, сравнительно-описательный, монографический, графический, контент-анализ и др.

Результаты. Объединяя навыки работников с целями организации, обращая внимание на условия труда, сохранение здоровья и трудовые обязанности и права, можно повысить производительность труда и избежать возможного банкротства. Менеджеры для достижения роста производительности труда должны применять на практике профессиональный опыт и продуктивные технологии, направленные на решение возникающих задач. Персонал, выполняющий работу вовремя, помогает начальнику справляться со сложной задачей управления персоналом, для решения которой организация несет временные, организационные и финансовые затраты. В большинстве случаев проблемы управления персоналом возникают по вине руководства, которое не всегда может грамотно руководить коллективом профессионалов: менеджеры не снимают проблемы, относя их к временным трудностям. 
Незнание трудовых прав работников и высших руководителей приводит к возникновению внутренних конфликтов. Для избежания подобных обстоятельств необходимо не только мониторить существующие проблемы, но и непрерывно обучаться методикам управления персоналом. Опытный руководитель не должен быть узким специалистом, так как он может допустить грубые ошибки при руководстве, не зная остальные внутренние отделы. В итоге роль управления рабочими кадрами начинает носить характер конфронтации по отношению к другим организационным отделам, а проблема текучести кадров остается одной из острых, так как организации не могут ее контролировать. Они нерационально используют работу персонала, неверно распределяют зарплату, безрассудно формируют кадровую политику, не привлекают к работе молодых специалистов.

В последние годы организация высокопроизводительных рабочих мест (ВПРМ) для любой компании остается приоритетным направлением в развитии управления персоналом. Данное направление активно начало развиваться и получило название «Задача-25», для достижения которой был проведен ряд мероприятий и конференций, где обсуждалась социальная значимость ВПРМ. Создание высокотехнологичных рабочих мест позволит усовершенствовать технологии управления персоналом и повысить рентабельность персонала в организациях.

В настоящее время важно, чтобы новые рабочие места были высокотехнологичными. Их внедрение формирует синергетический эффект: повысит эффективность труда, его производительность, уровень заработной платы, улучшит условия приложения знаний, умений и навыков. Для получения данного эффекта актуальны:

1. Оснащенность современным технологичным оборудованием.

2. Высокая экономическая эффективность производства.

3. Соответствующие должностным инструкциям условия труда.

4. Наличие высшего образования и высокой квалификации работников.

5. Высокая заработная плата персонала.

6. Высокая стоимость создания нового рабочего места.

Таким образом, создание благоприятных условий для внедрения ВПРМ служит важным отправным пунктом повышения производительности труда в организации. Уделим особое внимание оценке персонала как фактора успешности бизнеса. Оценка персонала взаимосвязана со следующими функциями управления им (рис. 1).

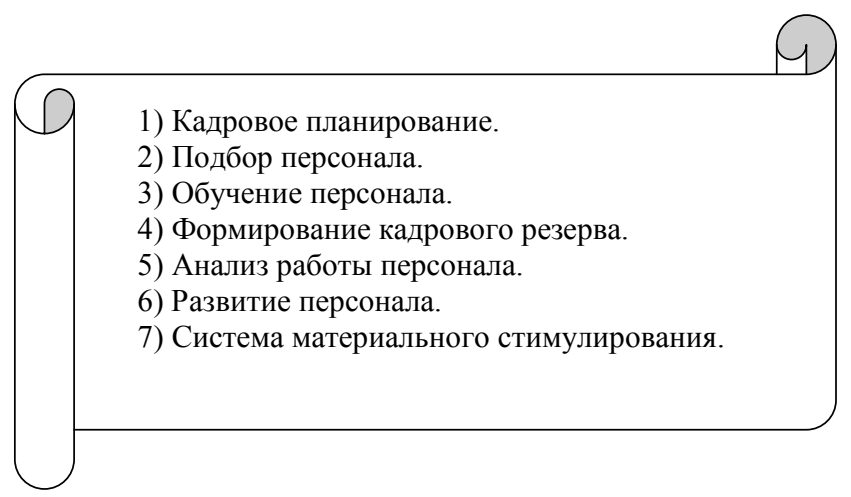

Рис. 1. Функции управления персоналом.

Теперь более подробно рассмотрим упомянутые функции.

1. Кадровое планирование: определение качественных и количественных рабочих показателей компании.

2. Подбор персонала: изучение эффективности методов привлечения новых сотрудников.

3. Обучение персонала: выявление наличия или отсутствия обучающих программ и необходимости дополнительного обучения персонала.

4. Формирование кадрового резерва: оценка работы сотрудников компании.

5. Анализ работы персонала: определение стандартов и показателей для оценки профессионального поведения сотрудников.

6. Развитие персонала: выявление профессионального потенциала сотрудников. 
7. Система материального стимулирования: оценка позволяет повысить эффективность стимулирующих факторов в управлении персоналом.

Выполнение всех вышеперечисленных функций положительно сказывается на эффективности работы как отдельных сотрудников, так и компании в целом. На сегодняшний день многие организации пересматривают подходы к оценке персонала. Рассмотрим уникальные аналитические данные о лучших практиках адаптации и управления высококвалифицированным персоналом. Ключевая HR-задача — прием на работу высокопроизводительных сотрудников. Эта задача особенно важна в меняющейся демографии и глобализации рабочей силы. Ожидается, что высокопроизводительные сотрудники повысят организационные возможности для инноваций и приведут организацию в соответствие с постоянно меняющимися обстоятельствами. В процессе реализации данной задачи у фирмы появляется ряд проблем. Во-первых, она вкладывает денежные средства в поиск и наем сотрудников - от посещения ярмарок высокого уровня до длительных и интенсивных процессов найма. Во-вторых, после найма сотрудников возникает ряд других вопросов. Будут ли нанятые сотрудники относиться к высокоэффективному персоналу, предлагая конкретные возможности для личного развития и позволяя им делать то, что они считают лучшим? Увеличивает ли это способность к инновациям, развитию, общей производительности организации?

Организации должны тщательно создавать инклюзивную среду и управлять ею (рис. 2).

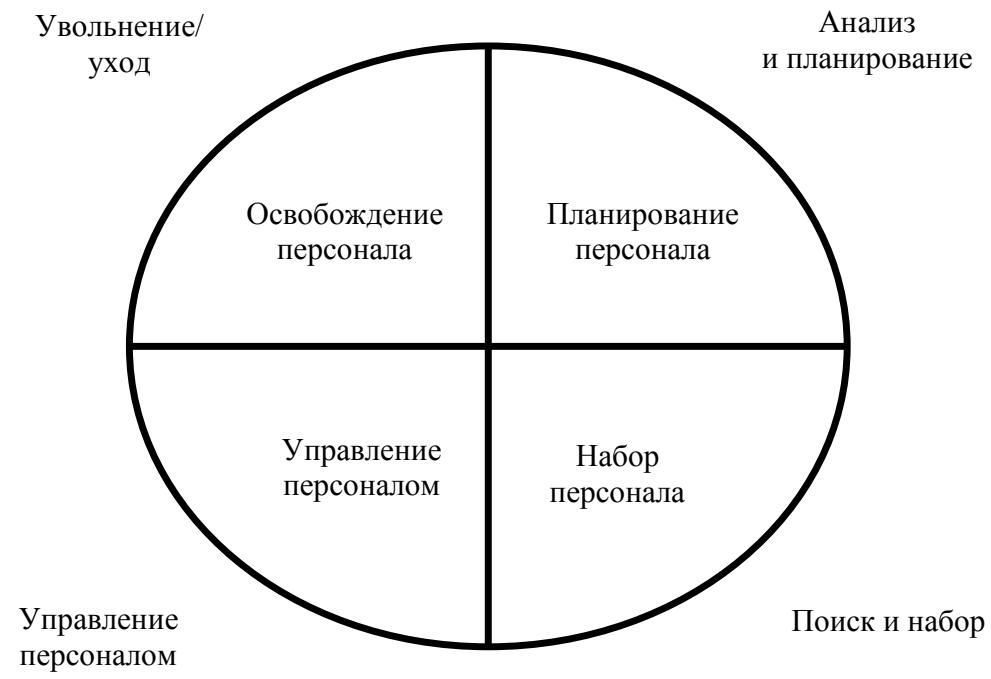

Рис. 2. Схема прочесса управления персоналом.

В настоящее время все больше компаний внедряют систему управления производительностью персонала, в рамках которой планируются еженедельные или ежемесячные встречи, где руководители и сотрудники обсуждают цели и прогресс компании. Организации должны придерживаться традиционного обзора эффективности управления персоналом для поддержания основных ценностей компании: прозрачности, открытости и справедливости. Новая технология управления персоналом позволяет работодателям быстрее и надежнее общаться с сотрудниками и разрабатывать инновационные тактики: предлагать бесплатное образование для сотрудников с помощью онлайн-курсов и тренеров (рис. 3). 
СЛЕПЦОВА Е.В., ТРОФИМЕНКО С.С., РОГАЧЕВ П.Д., КОНДАКОВ О.О.
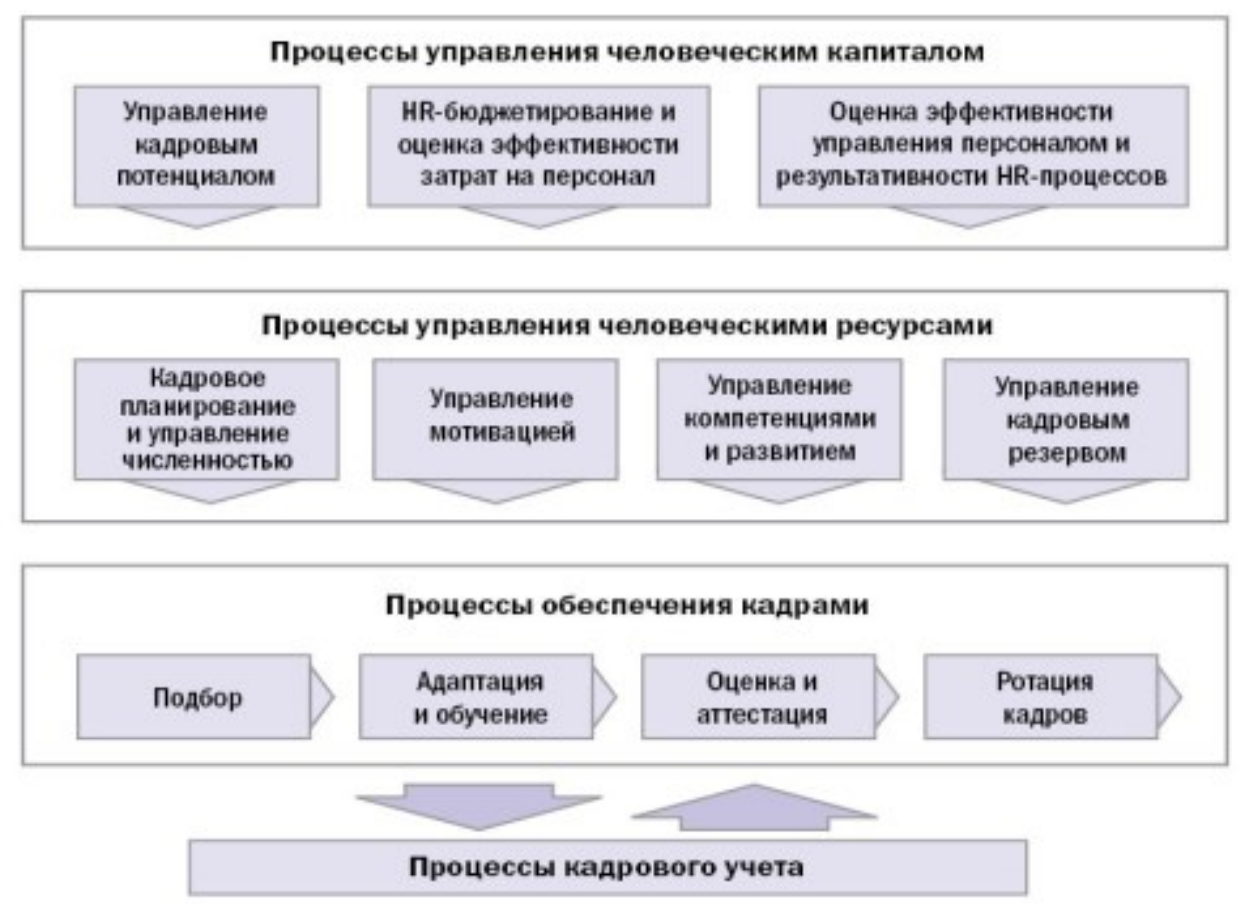

Puc. 3. Декомпозищия HR-прочессов.

Выводы. Дальнейшее формирование «Задачи-25» и модернизация высокотехнологичных рабочих мест позволят совершенствовать технологии управления персоналом. Модернизация структуры управления персоналом представляет собой сложную и ответственную задачу для руководства. Огромное значение имеет создание плана проекта, соответствующего внешним и внутренним условиям, в котором формулируются цели и задачи, необходимые для совершенствования, методы решения поставленных вопросов, социально-экономические критерии развития, а также оценка организации и ее внешней среды.

В современных нестабильных условиях хозяйствования развитие персонала, которое является неотъемлемым элементом стратегии управления персоналом, приобретает особую актуальность. Для многих компаний процесс стратегического развития работников отходит на задний план. Формирование и реализация эффективной стратегии управления персоналом остаются залогом не только развития самих работников, но и непосредственной предпосылкой экономического роста организации и ее стратегического развития.

Литература

1. Архипова Н. И. Управление персоналом организациии. Краткий курс для бакалавров / Н. И. Архипова, О. Л. Седова. - М.: Проспект, 2016. - 224 c.

2. Дудникова В. О., Захарова Л. Н. Мотивачия и стимулирование трудовой деятельности в управлении персоналом // Устойчивое развитие: общество и экономика. - 2016. - С. 37-40.

3. Кабанов А. Я. Управление персоналом: теория и практика. Организация профориентации и адаптации персонала: Учебно-практическое пособие / А. Я. Кабанов, Е. В. Каштанова. - М.: Проспект, 2015. - 56 с.

4. Кибанов А. Я., Баткаева И. А., Митрофанова Е. А. Управление персоналом: теория и практика. Мотивация и стимулирование трудовой деятельности: учебно-практическое пособие / под ред. А. Я. Кибанова // Москва: Проспект, 2016. - 64 c.

5. Кибанов А. Я., Захаров Д. К., Федорова И. А. Управление персоналом: теория и практика. Оиенка и отбор персонала при найме и аттестации, высвобождение персонала: учебно-практическое пособие / под ред. А. Я. Кибанова // Москва: Проспект, 2016. - 80 c.

6. Князева А. В., Гузиева Е. В., Захарова Л. Н. Теоретическое обоснование управления трудовыми ресурсами // Устойчивое развитие: общество и экономика. - 2016. - C. 51-54.

7. Кротова М. А., Вукович М. Д., Хатхоху М. А., Никитина А. . Пространственные трансформации как условие управления экономикой региона // Экономика устойчивого развития. - 2015. - № 2 (22). - C. $139-141$.

8. Кротова М. А., Рудченко А. М., Баркалова В. Ю., Овсюкова М. А. (2018). Инновационные методы анализа и оценки ключевых аспектов управления персоналом // Экономика устойчивого развития. — № 1 (33). - С. 256260.

9. Ладанов И. Д. Мотивационный климат организаџии / И. Д. Ладанов // Управление персоналом. - 2016. № 9. - С. 49-53.

10. Ладанов И. Д. Мотиваџионный климат организаџии / И. Д. Ладанов // Управление персоналом. - 2016. - 
№ 9. - C. 49-53.

11. Марченко Е. Ю., Никитина А. В., Рудченко А. М., Казарьян М. Ю. Исследование методических аспектов развития системы управления персоналом в современных условиях // Экономика устойчивого развития. 2017. - № 3 (31). - C. 205-209.

12. Молочников Н. Р., Пономаренко Е. Е. Трудовой потенциал в системе управления предприятием: проблемы и практика реализащии в условиях инновачионной экономики // Россия: тенденции и перспективы развития. Ежегодник. Институт научной информачии по общественным наукам Российской академии наук. Ответственный редактор - В. И. Герасимов. - 2018. - С. 305-307.

13. Павленко И. А., Гузиева Е. В., Никитина А. В. Стимулирование и мотивачия трудовой деятельности в управлении персоналом на современном предприятии // Экономика устойчивого развития. - 2016. № 2 (26). - C. 285-288.

14. Федосеев В. Н. Управление персоналом организации: учебное пособие / В. Н. Федосеев, С. Н. Капустин. М.: Экзамен, 2015. - 368 c.

15. Цыпкин Ю. А. Управление персоналом: учебное пособие для вузов / Ю. А. Цыпкин. - М.: ЮНИТИ-ДАНА, 2018. $-446 c$.

16. Шлендер П. Э., Маслова В. М., Смирнова М. Е. и др. Управление персоналом организащии: учебное пособие / под ред. П. Э. Шлендера. - М.: Вузовский учебник: ИНФРА-М, 2015.

17. Benedetta Gesuele, Mauro Romanelli. Human Resource Measurement: A Balanced Scorecard Approach //Journal of Human Resource Management. 2015; 3(2-1): 28-32. [An electronic resource]. Access mode: article. sciencepublishinggroup.com/pdf/10.11648.j.jhrm.s.20 15030201.14.pdf (дата обращения 20.04.2019), free. Heading from the screen.

18. Gebhart J. (2015). Global human resource management. Sloan Management Review. P. 38-40.

19. Popova D. A. (2018). Development of an algorithm for making management decisions based on situational analysis. Juvenisscientia. Vol. 12. P. 20-22.

20. Shahnawaz Saqib. (2015). Impact of Tangible and Intangible Rewardson Organizational Commitment: Evidence from the Textile Sector of Pakistan. American Journal of Industrial and Business Management. Vol. 15. P. $138-147$.

\section{References:}

1. Arhipova N. I. Upravlenie personalom organizacii. Kratkij kurs dlya bakalavrov / N. I. Arhipova, O. L. Sedova. M.: Prospekt, 2016. -224 c.

2. Dudnikova V. O., Zaharova L. N. Motivaciya i stimulirovanie trudovoj deyatel'nosti v upravlenii personalom // Ustojchivoe razvitie: obshchestvo i ekonomika. - 2016. - S. 37-40.

3. Kabanov A. YA. Upravlenie personalom: teoriya i praktika. Organizaciya proforientacii $i$ adaptacii personala: Uchebno-prakticheskoe posobie / A. YA. Kabanov, E. V. Kashtanova. - M.: Prospekt, 2015. - 56 c.

4. Kibanov A. YA., Batkaeva I. A., Mitrofanova E. A. Upravlenie personalom: teoriya i praktika. Motivaciya i stimulirovanie trudovoj deyatel'nosti: uchebno-prakticheskoe posobie / pod red. A. YA. Kibanova // Moskva: Prospekt, 2016. $-64 \mathrm{~s}$.

5. Kibanov A. YA., Zaharov D. K., Fedorova I. A. Upravlenie personalom: teoriya i praktika. Ocenka i otbor personala pri najme $i$ attestacii, vysvobozhdenie personala: uchebno-prakticheskoe posobie / pod red. A. YA. Kibanova // Moskva: Prospekt, 2016. - 80 s.

6. Knyazeva A. V., Guzieva E. V., Zaharova L. N. Teoreticheskoe obosnovanie upravleniya trudovymi resursami // Ustojchivoe razvitie: obshchestvo i ekonomika. - 2016. - S. 51-54.

7. Krotova M. A., Vukovich M. D., Hathohu M. A., Nikitina A. . Prostranstvennye transformacii kak uslovie upravleniya ekonomikoj regiona // Ekonomika ustojchivogo razvitiya. - 2015. - № 2 (22). - S. 139-141.

8. Krotova M. A., Rudchenko A. M., Barkalova V. YU., Ovsyukova M. A. (2018). Innovacionnye metody analiza i ocenki klyuchevyh aspektov upravleniya personalom // Ekonomika ustojchivogo razvitiya. — № 1 (33). - S. 256-260.

9. Ladanov I. D. Motivacionnyj klimat organizacii /I. D. Ladanov // Upravlenie personalom. - 2016. - № 9. - S. 49-53.

10. Ladanov I. D. Motivacionnyj klimat organizacii / I. D. Ladanov // Upravlenie personalom. - 2016. — № 9. - S. 49-53.

11. Marchenko E. YU., Nikitina A. V., Rudchenko A. M., Kazar'yan M. YU. Issledovanie metodicheskih aspektov razvitiya sistemy upravleniya personalom $v$ sovremennyh usloviyah // Ekonomika ustojchivogo razvitiya. — 2017. № 3 (31). - S. 205-209.

12. Molochnikov N. R., Ponomarenko E. E. Trudovoj potencial v sisteme upravleniya predpriyatiem: problemy i praktika realizacii v usloviyah innovacionnoj ekonomiki // Rossiya: tendencii i perspektivy razvitiya. Ezhegodnik. Institut nauchnoj informacii po obshchestvennym naukam Rossijskoj akademii nauk. Otvetstvennyj redaktor - V. I. Gerasimov. - 2018. - S. 305-307.

13. Pavlenko I. A., Guzieva E. V., Nikitina A. V. Stimulirovanie i motivaciya trudovoj deyatel'nosti v upravlenii personalom na sovremennom predpriyatii // Ekonomika ustojchivogo razvitiya. -2016 . - № 2 (26). - S. 285-288.

14. Fedoseev V. N. Upravlenie personalom organizacii: uchebnoe posobie / V. N. Fedoseev, S. N. Kapustin. - M.: Ekzamen, 2015. - 368 s.

15. Cypkin YU. A. Upravlenie personalom: uchebnoe posobie dlya vuzov / YU. A. Cypkin. - M.: YUNITI-DANA, 2018. $-446 c$.

16. SHlender P. E., Maslova V. M., Smirnova M. E. i dr. Upravlenie personalom organizacii: uchebnoe posobie / pod red. P. E. SHlendera. - M.: Vuzovskij uchebnik: INFRA-M, 2015.

17. Benedetta Gesuele, Mauro Romanelli. Human Resource Measurement: A Balanced Scorecard Approach //Journal of Human Resource Management. 2015; 3(2-1): 28-32. [An electronic resource]. Access mode: article. sciencepublishinggroup.com/pdf/10.11648.j.jhrm.s.20 15030201.14.pdf (data obrashcheniya 20.04.2019), free. Heading from the screen.

18. Gebhart J. (2015). Global human resource management. Sloan Management Review. P. 38-40.

19. Popova D. A. (2018). Development of an algorithm for making management decisions based on situational analysis. Juvenisscientia. Vol. 12. P. 20-22.

20. Shahnawaz Saqib. (2015). Impact of Tangible and Intangible Rewardson Organizational Commitment: Evidence from the Textile Sector of Pakistan. American Journal of Industrial and Business Management. Vol. 15. P. $138-147$. 